\title{
ASSESSMENT OF THRUST FROM PRESSURE MEASEREMENTS OF SUPERSONIC COMBUSTOR
}

\author{
Hwanil Huh* \\ Department of Aerospace Engineering, Chungnam National University \\ \#220 Gung-Dong, Daejeon 305-764, KOREA \\ Jungyong Kim ${ }^{\dagger}$ \\ Research Institute of Advanced Vehicle \\ Chungnam National University \\ \#220 Gung-Dong, Daejeon 305-764, KOREA \\ Yoo. Kim $\ddagger$ \\ Department of Mechanical Engineering, Chungnam National University \\ \#220 Gung-Dong, Daejeon, 305-764 Republic of Korea
}

and

James F. Driscoll§

Department of Aerospace Engineering, University of Michigan

Ann Arbor, MI 48109-2118

\begin{abstract}
The ideal vacuum thrust function is used to determine the local thrust of aerospace engine. Method of thrust determinationfrom measured pressures are applied to the model $\mathrm{M}=2.5$ supersonic combustor. In this application, measured pressures from the experiments in the University of Michigan are used to determine the local thrust of combustor. Marginal results of local thrust are obtained and compared with analytic calculation. Combustion and wedge affect thrust distributions in the upstream region. The thrust determination from pressure measurements can be a simple, feasible and applicable method, especially when thrust stand is not available.
\end{abstract}

\footnotetext{
* Assistant Professor. Member AIAA.

+ Researcher. Member AIAA.

$\ddagger$ Professor. Member AIAA.

§ Professor. Senior member AIAA.
}

Copyright $\odot 2002$ by the American Institute of Aeronautics and Astronautics Inc. All rights reserved.

\section{VACUUM THRUST OF JET PROPULSIONDEVICE}

The ideal thrust equation for a jet propulsion device can be derived from the general form of Newton's second law(i.e., force equals the time rate of change of momentum).

$$
F=\underset{d t}{d(m v)}
$$

The thrust acting on the engine is composed of two terms. The Momentum thrust is the product of the mass flow $\operatorname{rate}(\dot{m})$ and the exhaust velocity $\left(\nu_{e}\right)$ relative to the engine. The pressure thrust consists of the product of the exit pressure $\left(P_{e}\right)$ and the cross-sectional area of nozzle $\operatorname{exit}(\mathrm{A}$,$) . The resulting vacuum \operatorname{thrust}\left(F_{v}\right)$, assuming ideal one-dimensional flow, is

$$
F_{v}=\dot{m} v,+P_{e} A_{e}
$$

From the above equation, Hiers and Pruitt[1] 
developed the methodology to determine thrust from pitot pressure measurements. The following developments are from Hiers and Pruitt[ 13.

Since the mass flow rate is

$$
\dot{m}=\rho_{e} v_{e} A_{e}
$$

where $\rho_{e}$ is the exit plane density, Eq. (2) becomes

$$
\boldsymbol{4}=(\boldsymbol{p}-\boldsymbol{T}+\boldsymbol{L}
$$

From the equation of state for the perfect gas, Eq. (4) can be rewritten by

$$
F_{v}=\left(\frac{P_{e}}{R T_{e}} v_{e}^{2}+P_{e}\right) A,
$$

where $\mathrm{R}$ is the specific gas constant and $T_{\mathfrak{e}}$ is the exit plane temperature. Multiplying and dividing the first term within the parentheses by the ratio of specific heats $(\gamma)$ yields

$$
\left.F_{v}=\left(\begin{array}{c}
\gamma \frac{n^{2}}{e} \\
\gamma R T_{e}
\end{array}\right) 1\right) P_{e} A_{e}
$$

Speed of sound and Mach number are given by

$$
\begin{gathered}
a_{e}=\sqrt{\gamma R T_{e}} \\
M=\frac{v_{e}}{a_{e}}
\end{gathered}
$$

Substituting Eq. (7) and Eq. (8) into Eq. (6), Eq. (6) may be written as[2]

$$
F_{v}=\left(y M_{e}^{2}+1\right) P_{e} A_{e}
$$

Using Eq. (9), thrust can be determined from the static pressure measurement. However, Eq. (9) is very sensitive to variation of both the ratio of specific heats and the Mach number that would have to be determined by either numerical analysis or other measurements. This error is compounded by the static pressure measurements[1]. In Ref. [3] the probe method to measure both static and total pressures is recommended.

Therefore, Eq. (9) is rewritten in terms of pitot pressure $\left(P_{o 2}\right)$

$$
F_{v}=\left(r M_{e}^{2}+1\right) \frac{P_{e}}{P_{02}} P_{02} A_{e}
$$

If a pitot tube is in a supersonic freestream, the mouth of the pitot tube is a stagnation region. However, because the freestream is supersonic and the Pitot tube presents an obstruction to the flow, there is a strong bow shock wave in front of the tube. Hence, fluid element is decelerated nonisentropically to a subsonic velocity just behind the shock. Then it is isentropically compressed to stagnation condition. So, ratio of the measured pitot pressure behind the shock and freestream static pressure is given by

$$
\frac{P_{o 2}}{P_{e}}=\frac{P_{o 2}}{P_{2}} \frac{P_{2}^{v}}{P_{e}}
$$

From an isentropic relation

$$
\frac{P_{o 2}}{P_{2}}=\left(1+\frac{\gamma-1}{2} M_{2}^{2}\right)^{\gamma /(\gamma-1)}
$$

where

$$
M_{2}^{2}=\frac{1+[(\gamma-1) / 2] M_{e}^{2}}{\gamma M_{e}^{2}-(\gamma-1) / 2}
$$

Also, from the normal shock relation

$$
\frac{r_{2}}{P_{e}}=1+\frac{2 \gamma}{\gamma+1}\left(M_{e}^{2}-1\right)
$$

From the above equations (11) (14), Rayleigh Pitot tube formula can be derived for supersonic condition

$$
\frac{P_{e}}{P_{02}}=\left[\frac{2}{(\gamma+1) M_{e}^{2}}\right]^{\frac{\gamma}{\gamma-1}}\left[\frac{2 \gamma M_{e}^{2}-(\gamma-1)}{\gamma+1}\right]^{\frac{1}{\gamma-1}}
$$

If the freestream is a subsonic, compressible flow, the ratio of the static pressure to the pitot pressure from isentropic relation is given by Eq. (16)

$$
\frac{P_{e}}{P_{o 2}}=\left(1+\frac{\gamma-1}{2} M_{e}^{2}\right)^{-\gamma /(\gamma-1)}
$$

Now, Eq. (10) may be written as

$$
F_{v}=P_{02} A_{e} f\left(\gamma, M_{e}\right)
$$

For supersonic;

$$
\left[\begin{array}{l}
\left(\gamma, M_{e} \geq 1\right) \\
\left.\frac{2}{(y+1) M_{e}^{2}}\right]^{\frac{\gamma}{\gamma-1}}
\end{array}\left[\frac{2 \gamma M_{e}^{2}-(\gamma-1)}{\gamma+1}\right]^{\frac{1}{\gamma-1}}\left(\gamma M_{e}^{2}+1\right)\right.
$$

For subsonic;

$$
f\left(\gamma, M_{e}<1\right)=\left[1+\frac{\gamma_{y}=1}{2} M_{e}^{2}\right]^{\frac{-y}{\gamma-1}}\left(\gamma M_{e}^{2}+1\right)
$$

The function $f$ is termed the pitot pressure thrust function. Hiers and Pruitt[1] showed that the pitot pressure thrust function( $f$ ) was relatively insensitive to both Mach number and ratio of specific heats, up to Mach 2. Also they showed that the pitot pressure thrust function was insensitive to moderate changes in chamber pressure and mixture ratio for a typical rocket flow using axisymmetric, viscous, chemically reacting CFD model. 


\section{EXPERIMENTAL METHODS}

The supersonic combustor designed, constructed, and tested by Huh $[4,5]$ is employed for assessment of thrust from the pressure measurements. Figure 1 shows the schematic of the supersonic combustor in the University of Michigan. The bluff body fuel tube has an outer diameter of $25.4 \mathrm{~mm}$ and inner diameter $\left(\mathrm{d}_{\mathrm{F}}\right)$ of $7 \mathrm{~mm}$. The combustor length is $27.3 \mathrm{~cm}$. Combustor sidewalls diverge at $4^{\circ}$ from the axis in order to prevent thermal choking. Two identical wedges are mounted on the side walls of the combustor in order to interact the planar oblique shock waves with the hydrogen-air jet like flame.

Air is injected at static temperature of $284 \mathrm{~K}$ and stangnation pressure of $\mathbf{6 . 4 4 a t m}$ as shown in Table 1 .

As shown in Fig. 2, thirty four static pressure taps are placed $3.50 \mathrm{~cm}\left(5.0 \mathrm{~d}_{\mathrm{F}}\right)$ apart in the axial direction and 1.4 $\mathrm{cm}\left(2.0 \mathrm{~d}_{\mathrm{F}}\right)$ apart in the $\mathrm{Y}$ (traverse) direction to measure the wall static pressures. Each static pressure tap was designed so that it can be removed and replaced with a pitot pressure probe which has a $0.1 \mathrm{~cm}$ inner diameter; therefore, local Mach number distribution can be obtained. Pitot pressures as well as wall static pressures are measured and reported[6].

\section{PRESSURE ASUREMENT}

Figure 3 represents wall static pressure distributions. With combustion, wedge affects the wall static pressure in the upstream region $\left(\mathrm{X} / \mathrm{d}_{\mathrm{F}}<10\right)$ and in the downstream region $\left(X / d_{F}>10\right)$ in different manner[5, 6]. In the upstream region where flame-stabilizing mechanism is important, pressures are greater for the wedge case as comparing Fig. 5(a) with Fig. 5(c). In the downstream region, which is important for combustion efficiency, pressures are lower for the wedge case. In this region, expansion waves from the step create a radial outflow of fuel away from the central reaction zone, which reduces the residence time and results in decreased combustion efticiency as reported by Ratner, et al.[7].

Normalized pitot pressure contours are shown in Fig. 4,5 , and 6 . Heat release increases the pitot pressures near the wall as in Fig. 6, while in the center(within the flame, see Fig. 3) heat release tends to decrease the pitot pressure. However, the effects of heat release on the pitot pressure distribution are not clear[6].

\section{ASSEESSMENT OF THRUST FROM PRESSURE MEASUREMENTS OF THE SUPERCONIC COMBUSTOR}

\section{Methodolow}

Pitot pressures are measured at the location as shown in Fig. 7. The local planes for pitot pressure measurement are 5 locations starting from $5.0 \mathrm{~d}_{\mathrm{F}}$ to $25.0 \mathrm{~d}_{\mathrm{F}}$.

Local planes are divided into the number of locations of pitot pressure measurements, so that each measured pitot pressure represents the total pressure of assigned region. Local Mach numbers are obtained from wall static pressure data. From the Eq. (17) with measured pitot pressure and calculated local Mach number, local value of thrust is computed. The sum of each thrust is the total thrust of each local plane. The assumptions for thrust calculation are as follows.

1. Uniform one-dimensional flow through combustor.

2. Local static pressures on the local plane is equal to wall static pressure.

(No static pressure data inside the combustor are obtained in experiment of the University of Michigan).

3. The sum of each thrust is the total thrust of each local plane.

Theoretical adiabatic flame temperature of Hydrogenair is about $2400 \mathrm{~K}$. However, in the actual combustion, flame temperature is about $1700 \mathrm{~K}$ because of heat loss to the wall. Therefore, we use the ratio of specific heats as a constant value; $\gamma=1.4$ for no combustion case and $\gamma=9 / 7$ for combustion case.

\section{Results and Discussion}

Table 2 shows the computed results of the local thrust distributions for with/without combustion and with/without wedge case.

Order of magnitude of thrust at the combustor inlet is compared to local thrust of no combustion without wedge at $X / d_{F}=5$. By using Eq. (11), the overall thrust at the fuel exit plane can be calculated

$$
F_{y}=m v=0.94 \times 603=567 \mathrm{~N}
$$

Order of magnitude for two cases is similar, even though thrust of no combustion without wedge at $\mathrm{X} / \mathrm{d}_{\mathrm{F}}=5$, $549.8 \mathrm{~N}$, is not the actual inlet thrust. From this result, thrust is considered to be properly calculated.

Results of local thrust are plotted in Fig. 8 and Fig. 9. Actual thrust of combustor should be measured at further downstream location. Combustion and wedge affect thrust distributions in the upstream region, especially for wedge case; oblique shock generated from the wedge affect thrust distributions. However, in the Michigan experiment, there is no data over $X / d_{F}=25$, so that the actual thrust of combustor is not clear. 


\section{Analvtical modification of pitot pressure thrust function}

Local static pressures on the local plane are assumed equal to the wall static pressure, To modify this assumption, thrusts are calculated using the analytically computed Mach number for no combustion with wedge case, and shown in Fig. 10 and table 3.

In Fig. 11, the local values of the thrust are somewhat different, but the overall thrust distribution is similar. From this result, we conclude that the assessment of thrust from the pressure measurements can be reasonable method to determine the thrust of ajet propulsion device

\section{CONCLUSIONS AND FUTURE WORK}

Thrust determination from pressure measurements of a supersonic combustor is conducted and compared with analytic calculation. Both methods show reasonably good agreement in a limited case. The thrust determination method from pressure measurements can be a simple, feasible and applicable method, especially when thrust stand is not available.

Validation of thrust determination from pitot pressures can be achieved by comparing the actual thrust measurement from thrust stand. For preliminary study, small-scale thrust stand is designed and tested to measure the thrust of model rocket motor as shown in Fig. 12 and 13. Thrust measurements of different types and conditions of model rocket motors are already done and appropriate results are obtained.

In order to validate the thrust measurement from pitot pressures, small-scale supersonic wind tunnel is installed on the thrust stand as shown in Fig. 13 and 14. Actual thrust will be measured on the thrust stand while pressures are measured simultaneously. Then, actual thrust will be compared with the thrust from pressure measurements.

\section{ACKNOWLEGEMENT}

This work was partially supported by grant No. KOSEF R01-2000-00316 from the basic research program of the Korea Science \& Engineering Foundation.

\section{$\underline{\text { References }}$}

[1] Hiers, D., and Pruitt, D., "Determination of Thrust from Pitot Pressure Measurements," AIAA 20013314, The $32^{\text {nd }}$ ALAA/ASME/SAE/ASEE Joint Porpulsion Conference and Exhibit, Salt Lake City, UT., July 8-11,2001.

[2] Sforzino, R. H., "Derivation of the Thrust Equation from Conservation of Energy," Journal of Aircraft, Vol. 7, No. 5, 1970, pp. 538-540.

[3] MIDAP Study Group, "Guide to In-Flight Thrust Measurement of turbojets and Fan Engines," AGRADorgaph No. 237, 1979, pp. 94-95.

[4] Huh, H, Driscoll, J. F., "Measured Effects of Shock Waves on Supersonic Hydrogen-Air Flames," AIAA Paper 96-3035, The $32^{\text {nd }}$ AIAA/ASME/SAE/ ASEE Joint Porpulsion Conference and Exhibit, Lake Buena Vista, FL., July 1-3,1996.

[5] Huh, H., An Experimental Study of Supersonic Hydrogen-Air Flames for Scramjet Applications, Ph.D. Thesis, The University of Michigan, 1996.

[6] Huh, H. Kim, J., and Driscoll, J. F., "Measured Characteristics of Flow and Combustion in Supersonic Flame/Shock Wave Interaction," AIAA Paper 2001-3314, The 37th AIAA/ASME/SAE/ ASEE Joint Propulsion Conference and Exhibit, Salt Lake City, UT, USA, July 8-11,2001.

[7] Ratner, A. Driscoll, J. F., Huh, H., and Bryant, R. A., "Combustion Efficiencies of Supersonic Flames," $J$. of Propulsion and Power, Vol. 17, No. 2, 2001, pp. 301-307.

[8] Heiser, W. H., and Pratt, D. T., Hypersonic Airbreathing Propulsion, AIAA education series, 1994.

[9] Shapiro, A. H., The Dynamics and Thermodynamics of Compressible Fluid Flow, Ronald Press, New York, 1953. 


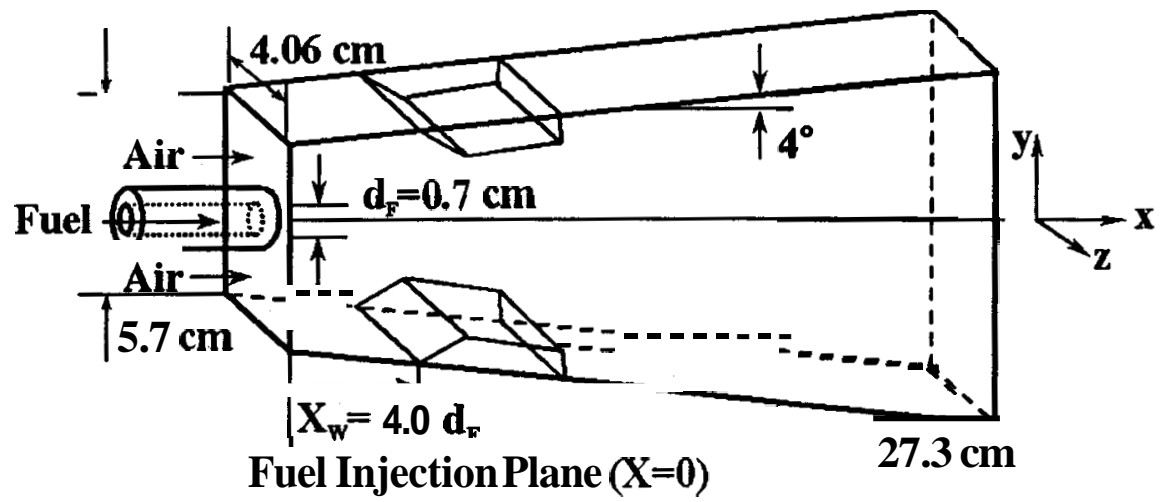

Fig. 1 Schematic diagram of supersonic combustor

Table 1. Typical boundary condition at the fuel injection $(x=0, \phi=0.035)$

\begin{tabular}{l|c}
\hline \hline Air Mach Number, $\mathrm{M}_{\mathrm{A}}$ & $\mathbf{2 . 5}$ \\
Air StagnationTemperature, $\mathrm{T}_{\mathrm{oA}}(\mathrm{K})$ & $\mathbf{2 8 4}$ \\
Air Stagnation Pressure, $\mathrm{P}_{\mathrm{o}}(\mathrm{atm})$ & 6.44 \\
Air Mass Flow rate, $\dot{m}_{A}(\mathrm{~kg} / \mathrm{s})$ & 0.94 \\
Air Velocity, $\mathrm{U}_{\mathrm{A}}(\mathrm{m} / \mathrm{s})$ & 603 \\
Fuel Mass Flow rate, $\dot{m}_{F}(\mathrm{~kg} / \mathrm{s})$ & 0.96 \\
Fuel Mach Number, $\mathrm{M}_{\mathrm{F}}$ & 1.0 \\
\hline
\end{tabular}

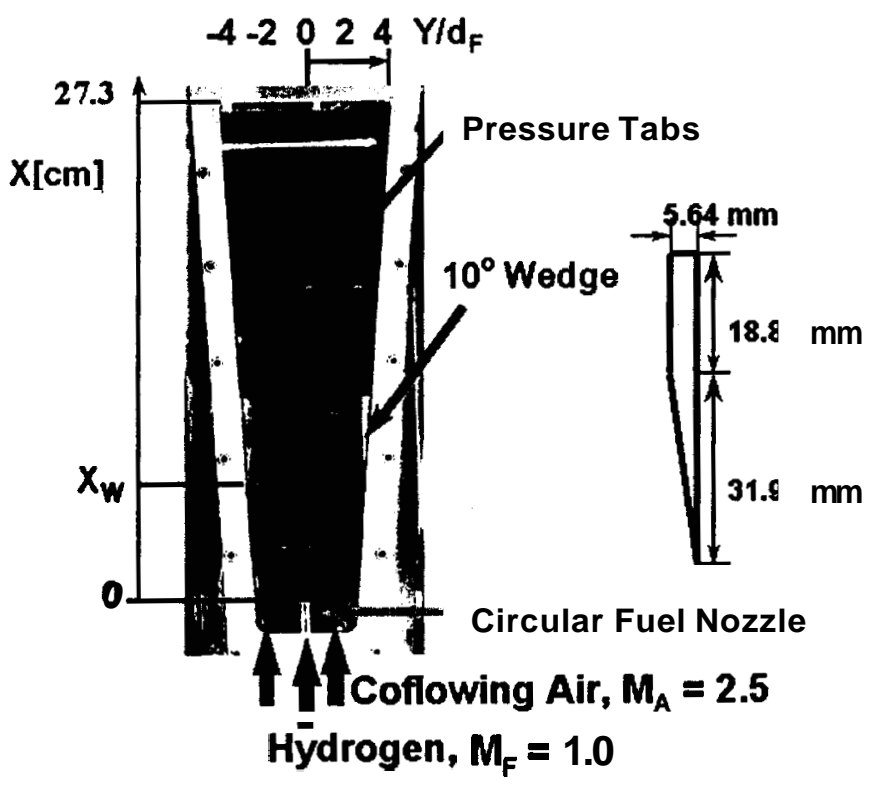

Fig. 2. Photograph of supersonic combustor 


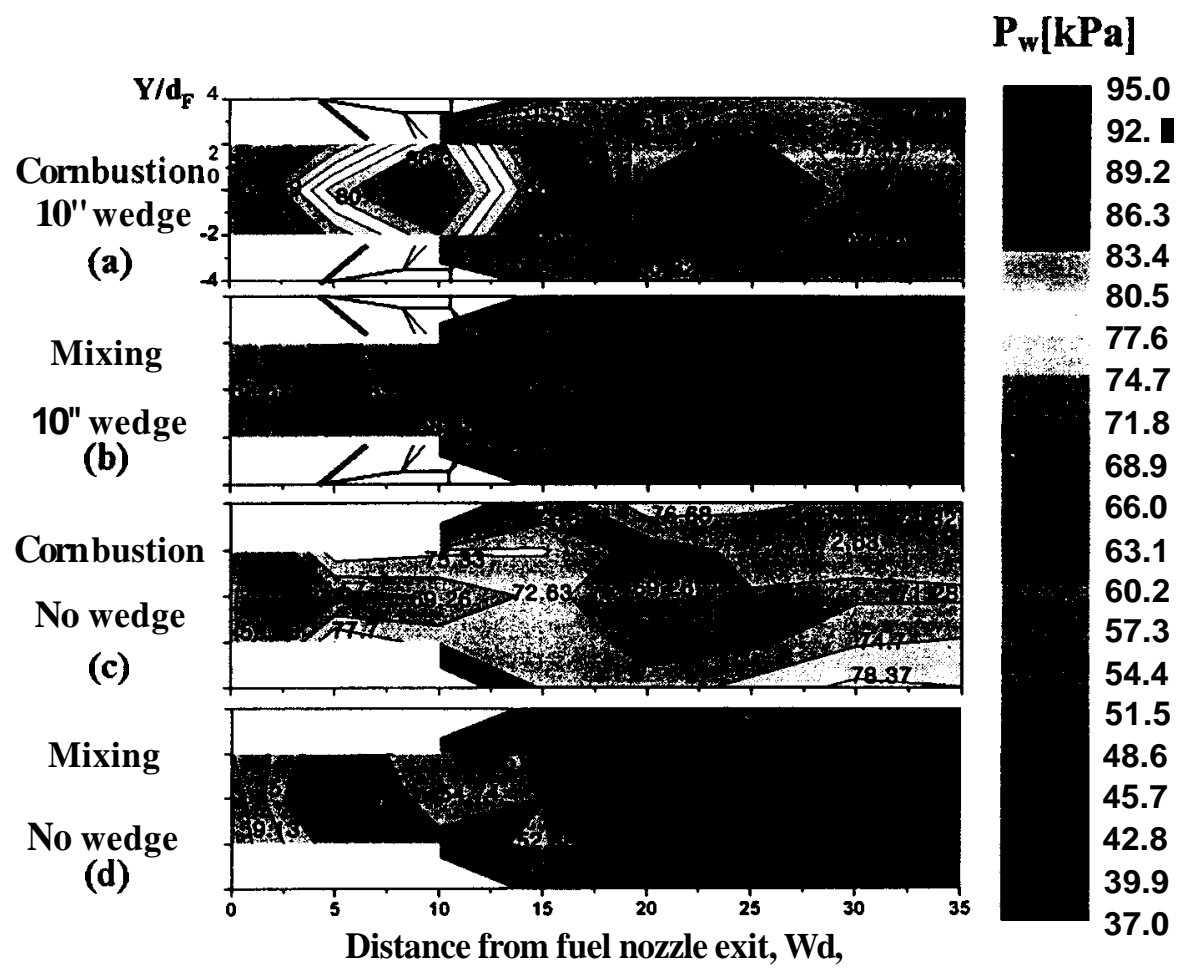

Fig. 3 Wall static pressure (P,) contours. $\phi=0.035$

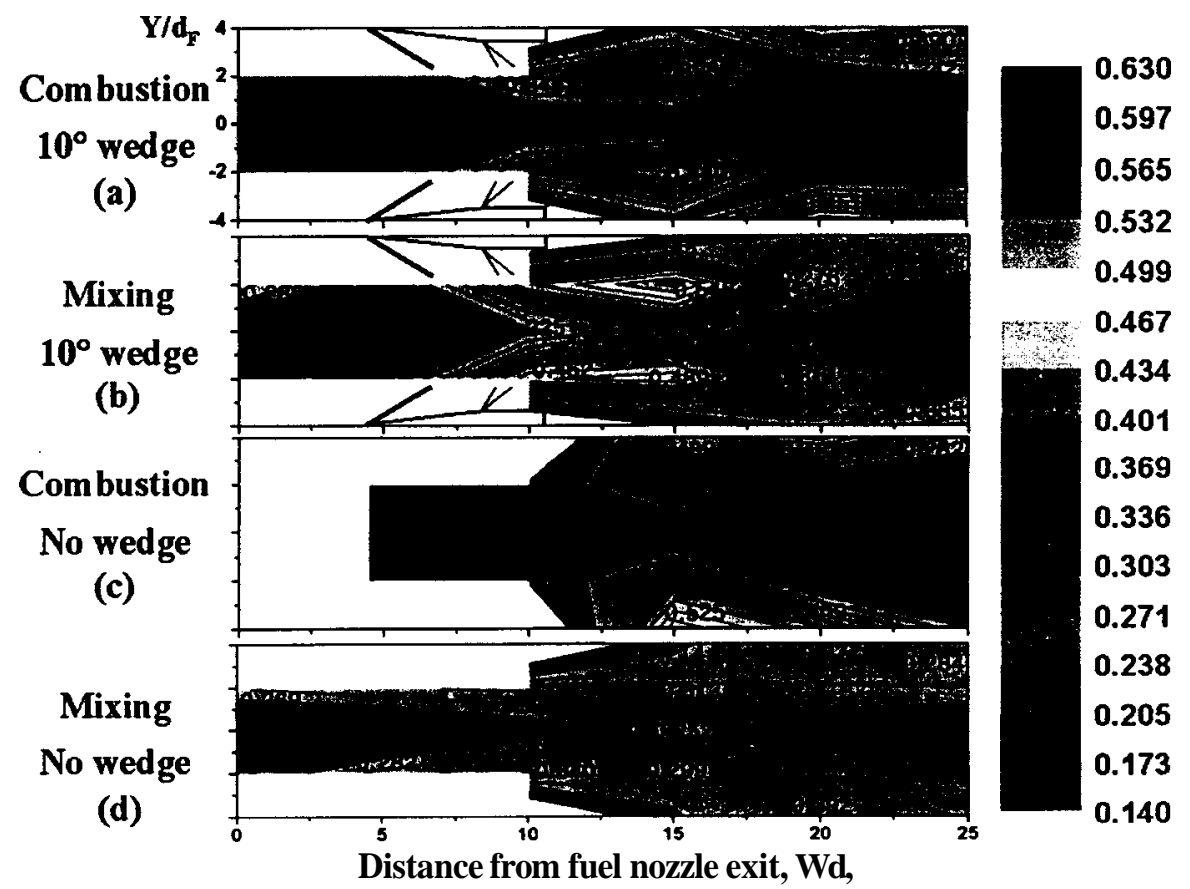

Fig. 4 Normalized pitot pressure $\left(\mathbf{P}_{\mathbf{t}} / \mathbf{P}_{\mathbf{o}}\right)$ contours. $\mathbf{Z} / \mathbf{d}_{\mathrm{F}}=0$ (center) 


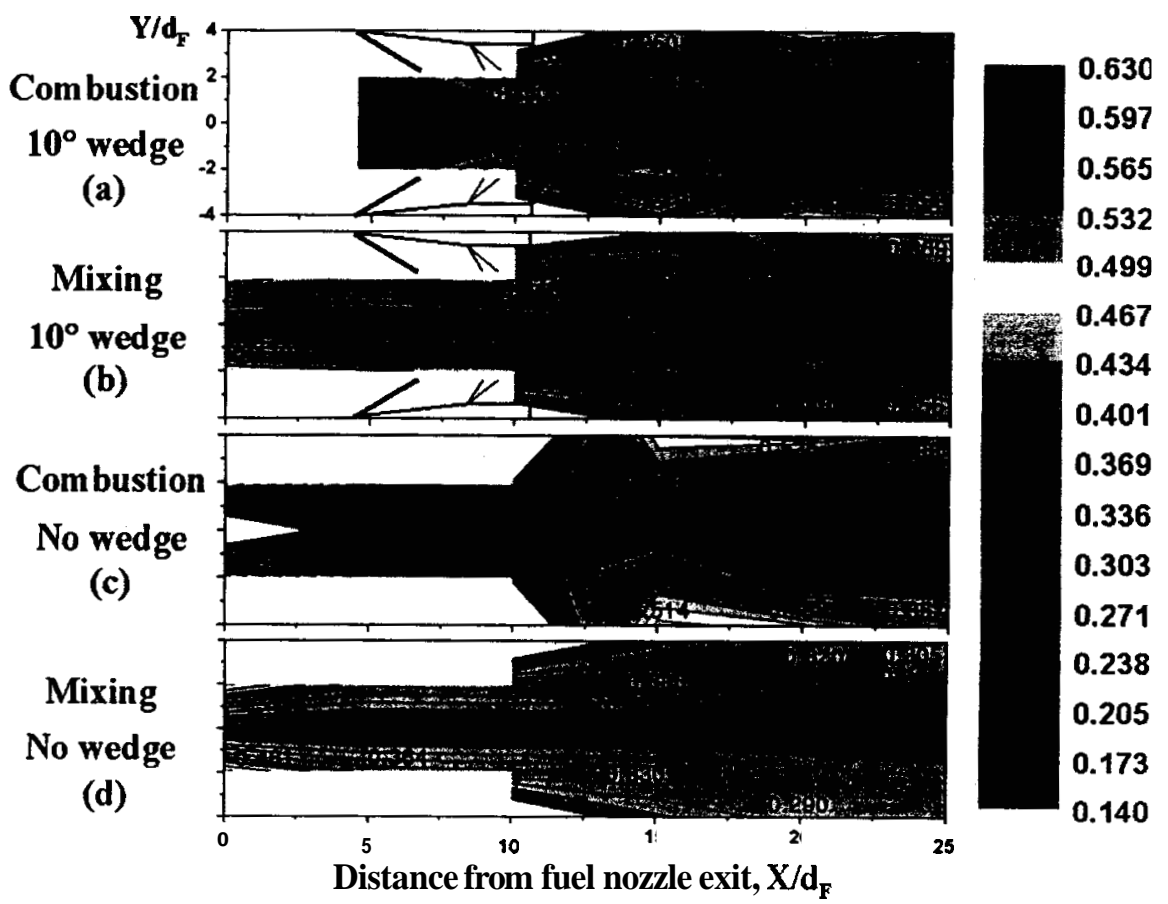

Fig. 5 Normalized pitot pressure $\left(P_{t} / P_{0}\right)$ contours. $Z / d_{\bar{F}}=1.3(1 / 2$ center $)$

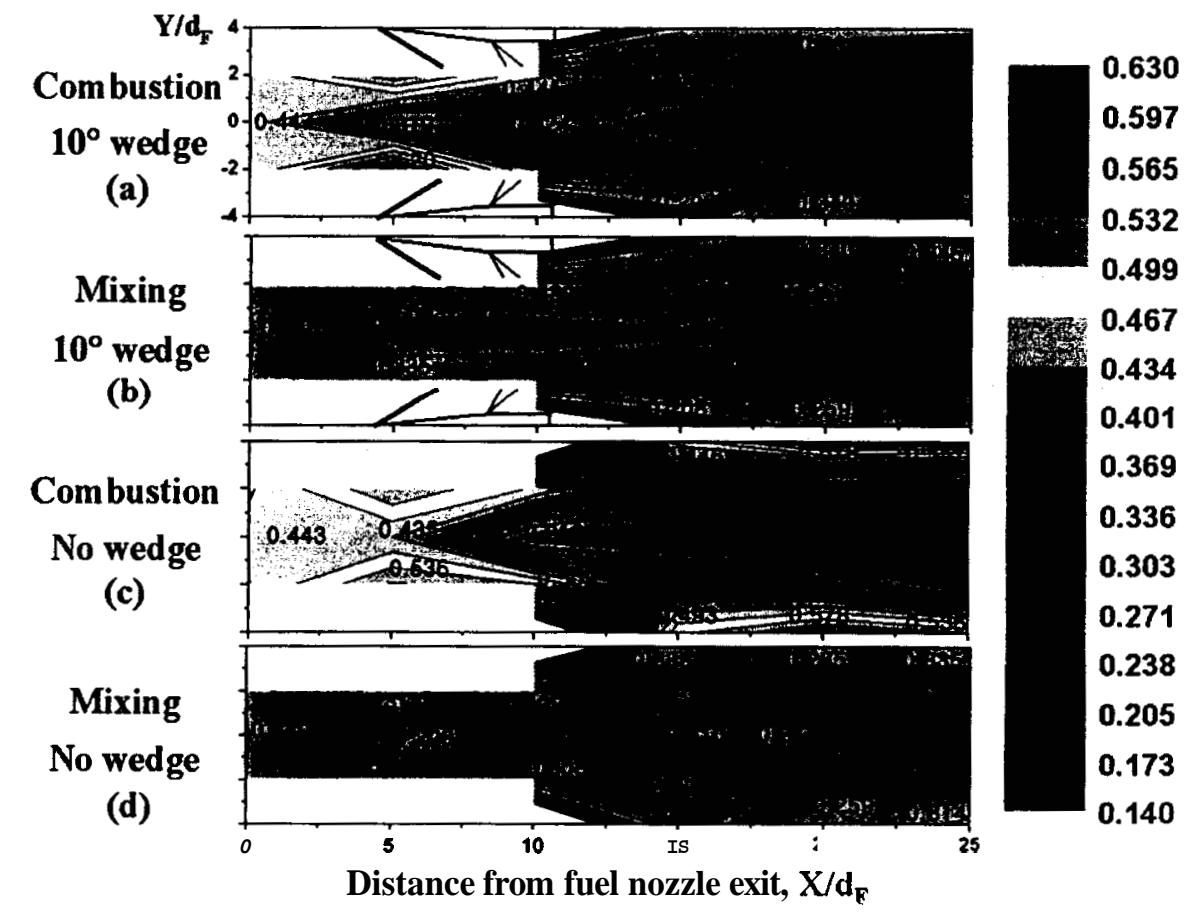

Fig. 6 Normalized pitot pressure $\left(\mathrm{P}_{\mathbf{t}} / \mathrm{P}_{\mathbf{0}}\right)$ contours. $\mathrm{Z} / \mathrm{d}_{\mathrm{F}}=2.6$ (near wall) 


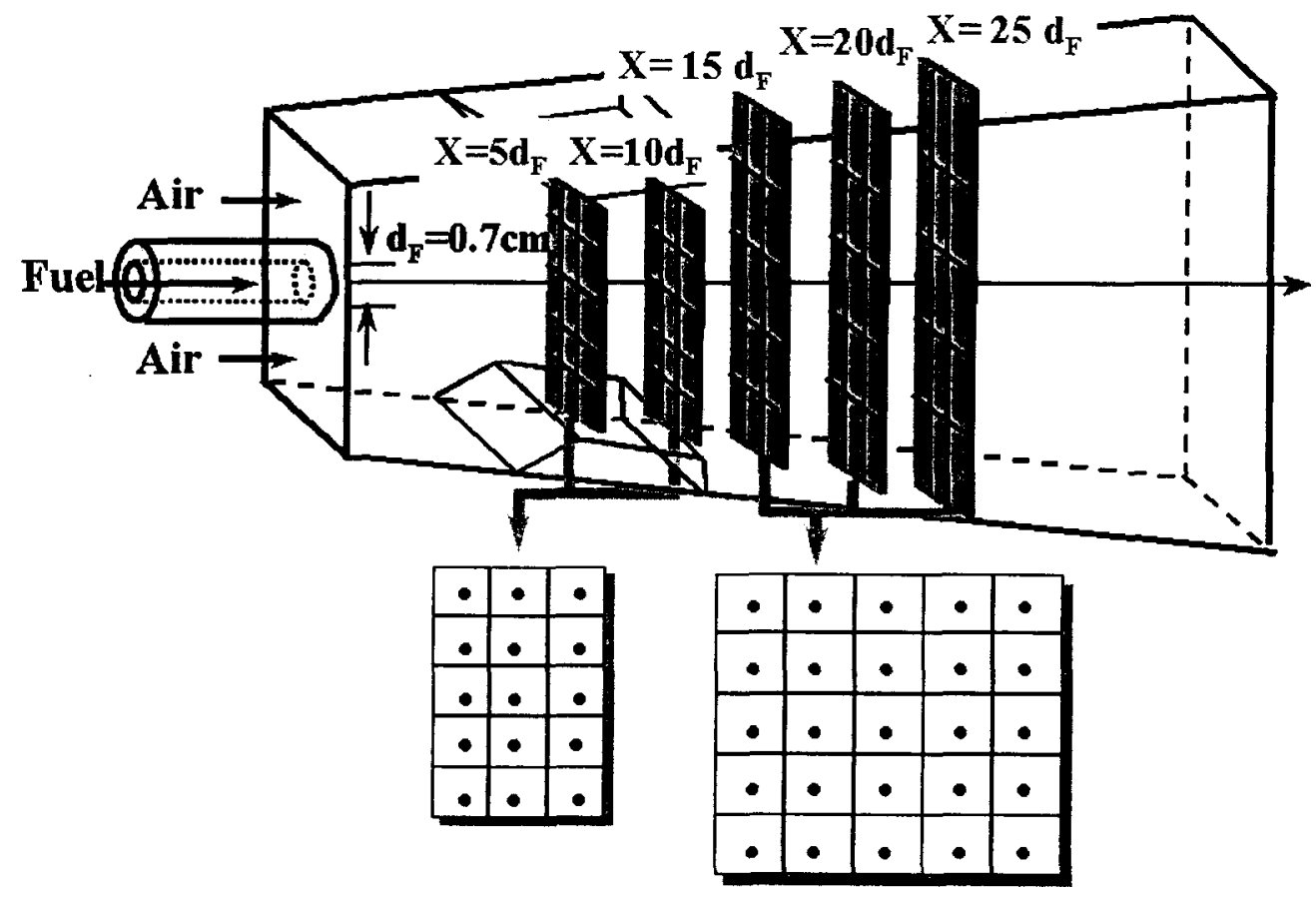

Fig. 7 Pitot pressure measurements at the local cross-sectional area of combustor

Table 2. Local thrust distribution at the planes of pitot pressure measurements

\begin{tabular}{cccccc}
\hline \hline & $\mathbf{X} / \mathbf{d}_{\mathbf{F}}=\mathbf{5}$ & $\mathbf{X} / \mathbf{d}_{\mathbf{F}}=\mathbf{1 0}$ & $\mathbf{X} / \mathbf{d}_{\mathbf{F}}=\mathbf{1 5}$ & $\mathbf{X} / \mathbf{d}_{\mathbf{F}}=\mathbf{2 0}$ & $\mathbf{X} / \mathbf{d}_{\mathbf{F}}=\mathbf{2 5}$ \\
\hline $\begin{array}{c}\text { Without wedge } \\
\text { No combustion }\end{array}$ & $\mathbf{5 4 9 . 8 \mathrm { N }}$ & $675.9 \mathrm{~N}$ & $656.4 \mathrm{~N}$ & $658.3 \mathrm{~N}$ & $652.1 \mathrm{~N}$ \\
$\begin{array}{c}\text { Without wedge } \\
\text { Combustion }\end{array}$ & $\mathbf{6 1 1 . 6 \mathrm { N }}$ & $530.7 \mathrm{~N}$ & $845.1 \mathrm{~N}$ & $760.0 \mathrm{~N}$ & $658.0 \mathrm{~N}$ \\
$\begin{array}{c}\text { With wedge } \\
\text { No combustion }\end{array}$ & $540.5 \mathrm{~N}$ & $725.0 \mathrm{~N}$ & $658.6 \mathrm{~N}$ & $663.1 \mathrm{~N}$ & $633.9 \mathrm{~N}$ \\
$\begin{array}{c}\text { With wedge } \\
\text { Combustion }\end{array}$ & $565.1 \mathrm{~N}$ & $698.2 \mathrm{~N}$ & $642.8 \mathrm{~N}$ & $637.4 \mathrm{~N}$ & $625.0 \mathrm{~N}$ \\
\hline \hline
\end{tabular}




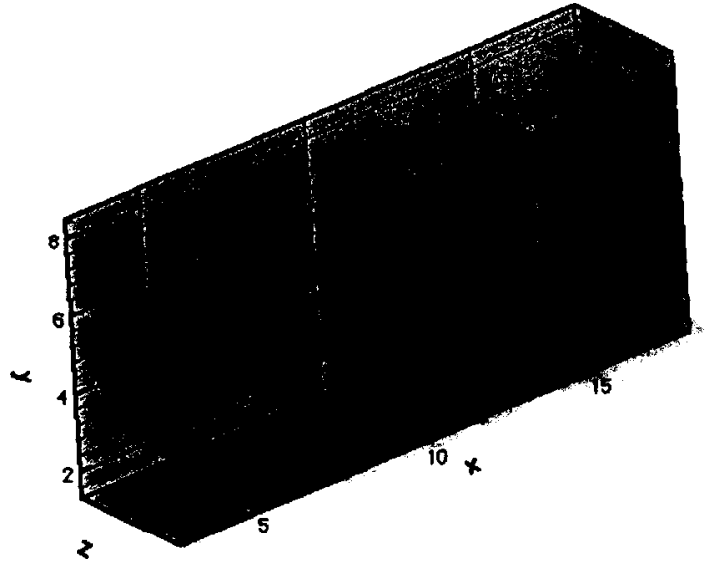

(a) No combustion

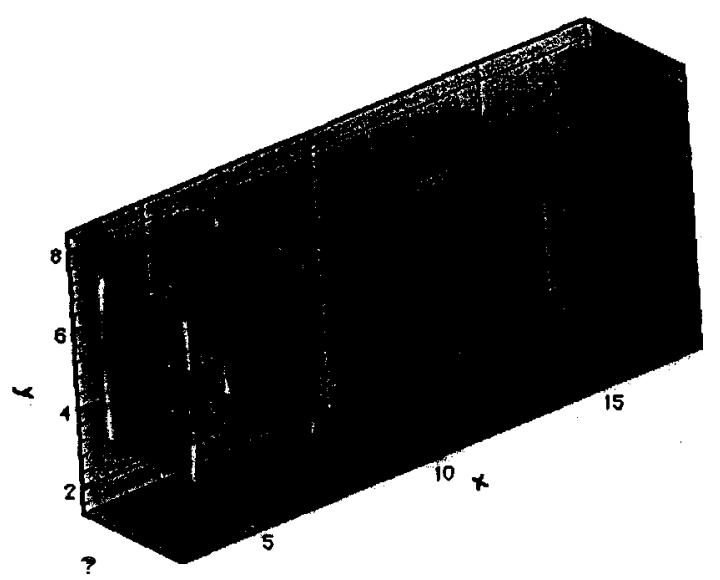

(b) Combustion

\section{3)}

1.t.

14.017 .520 .924 .427 .931 .434 .838 .341 .845 .348 .752255 .759 .262 .666 .169 .673 .176 .580 .0

Fig. 8 Thrust distribution for no wedge case

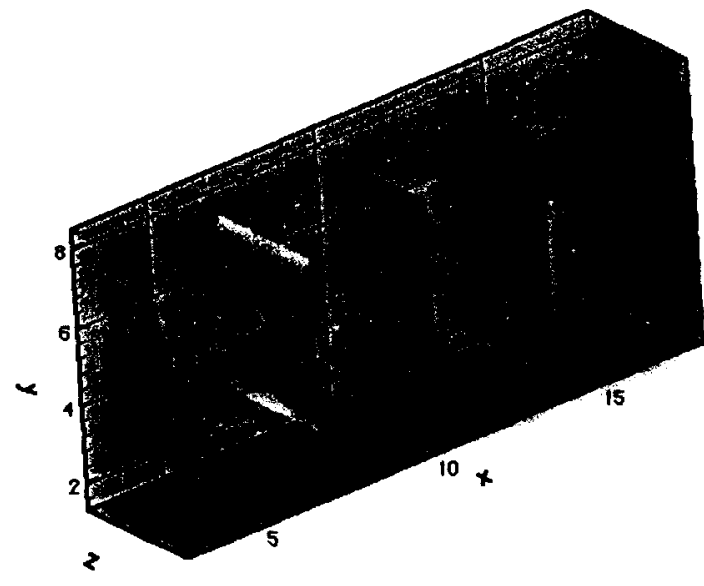

(a) No combustion

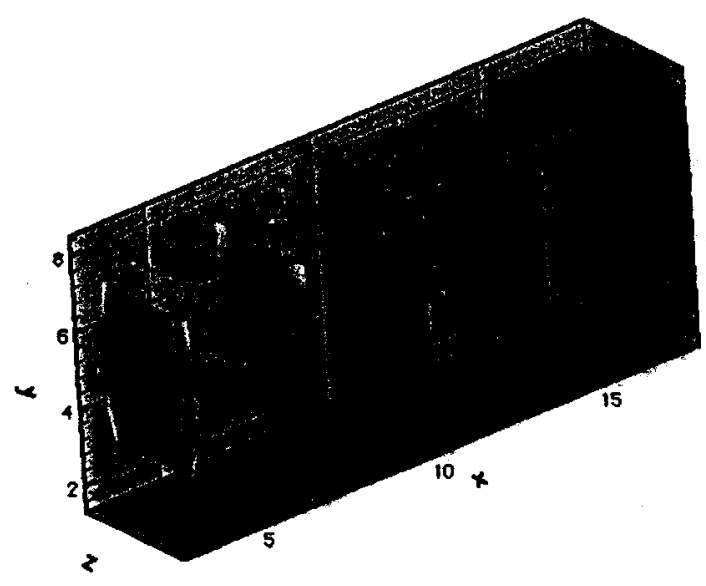

(b) Combustion

\section{S)}

14.017 .520 .924 .427 .931 .434 .838 .341 .845 .348 .752255 .759 .262 .666 .169 .673 .176 .580 .0

Fig. 9 Thrust distribution for wedge case 


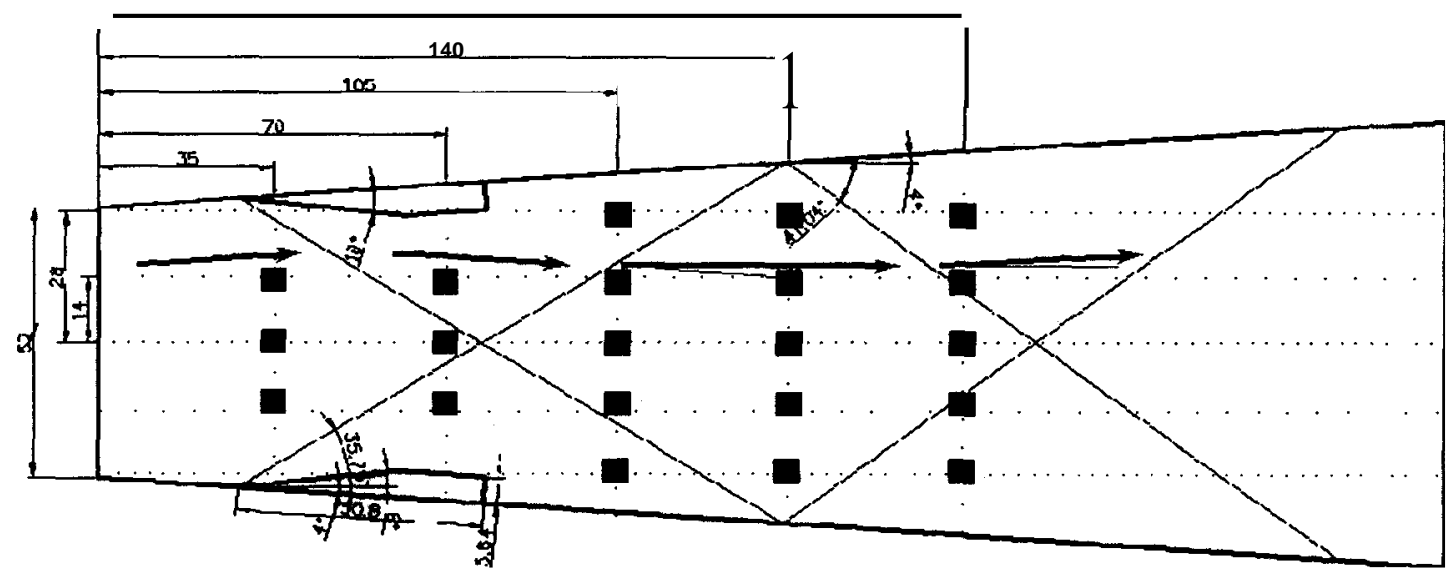

Fig. 10Analytical calculation of Mach number

Table. 3 Analytical Mach number for no combustion with wedge case

\begin{tabular}{|c|c|c|c|c|c|}
\hline & $\mathrm{X} / \mathrm{d}_{\mathrm{F}}=5$ & $\mathrm{X} / \mathrm{d}_{\mathrm{F}}=10$ & $\mathrm{X} / \mathrm{d}_{\mathrm{F}}=15$ & $\mathrm{X} / \mathrm{d}_{\mathrm{F}}=20$ & $\mathrm{X} / \mathrm{d}_{\mathrm{F}}=25$ \\
\hline $\mathrm{Y} / \mathrm{d}_{\mathrm{F}}=4$ & - & & 1.82 & 1.66 & 1.53 \\
\hline $\mathrm{Y} / \mathrm{d}_{\mathrm{F}}=2$ & 2.2 & 1.82 & 1.66 & 1.66 & 1.53 \\
\hline $\mathrm{Y} / \mathrm{d}_{\mathrm{F}}=0$ & 2.2 & 2.2 & 1.66 & 1.66 & 1.66 \\
\hline $\mathrm{Y} / \mathrm{d}_{\mathrm{F}}=-2$ & 2.2 & 1.82 & 1.66 & 1.66 & 1.53 \\
\hline $\mathrm{Y} / \mathrm{d}_{\mathrm{F}}=-4$ & & & 1.82 & 1.66 & 1.53 \\
\hline
\end{tabular}

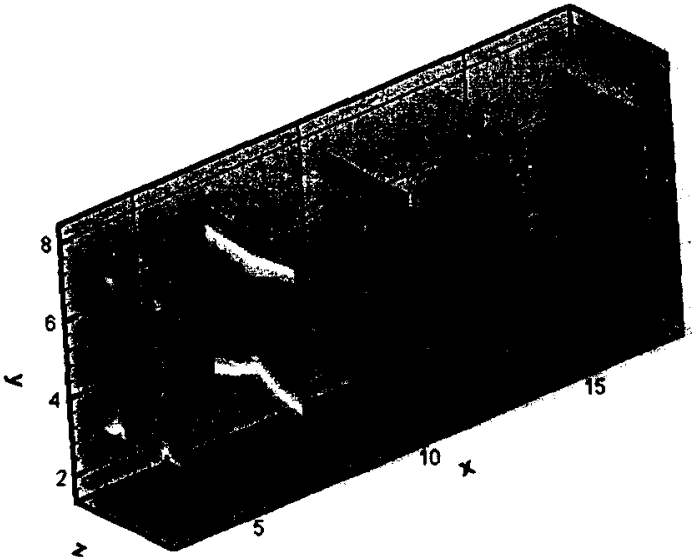

(a) Thrust distribution from Mach number based on wall static pressure

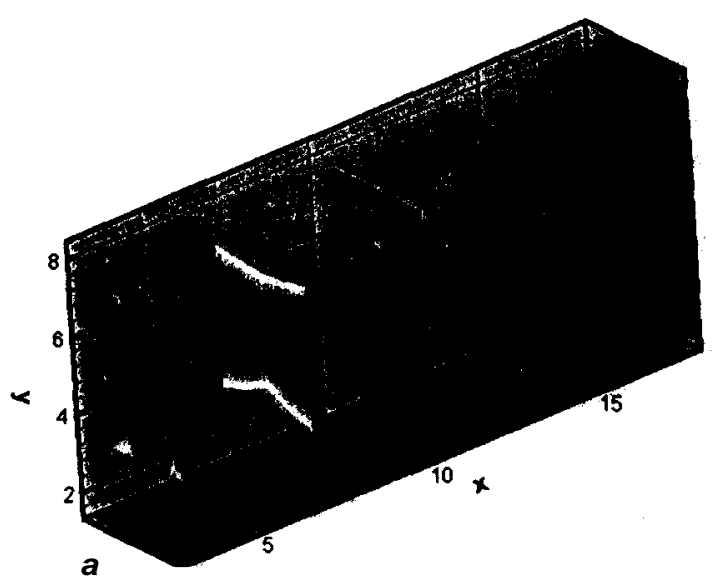

@) Analytically Modified thrust distribution

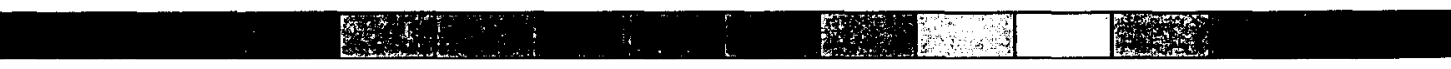

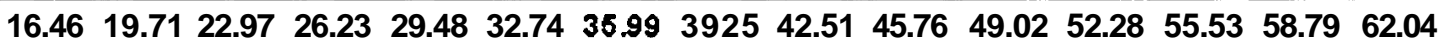

Fig. 11 Comparison of the thrust from wall static pressure and the thrust from analyticallycomputed Mach number 


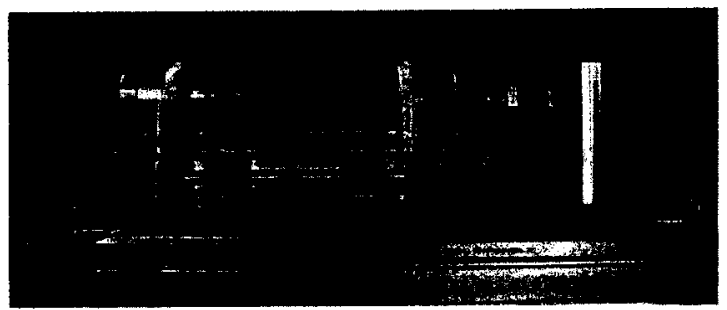

(a) Photograph of thrust stand

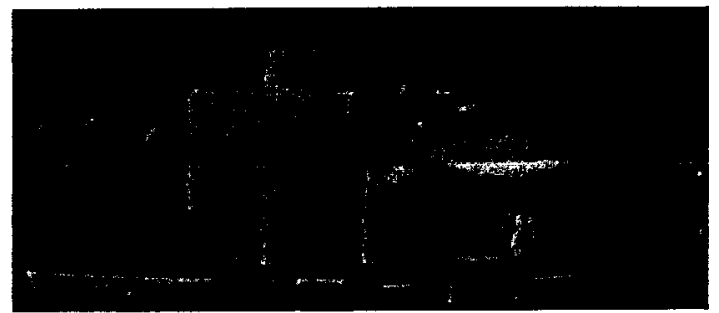

(b) Fire test of model rocket motor

Fig. 12 Thrust stand

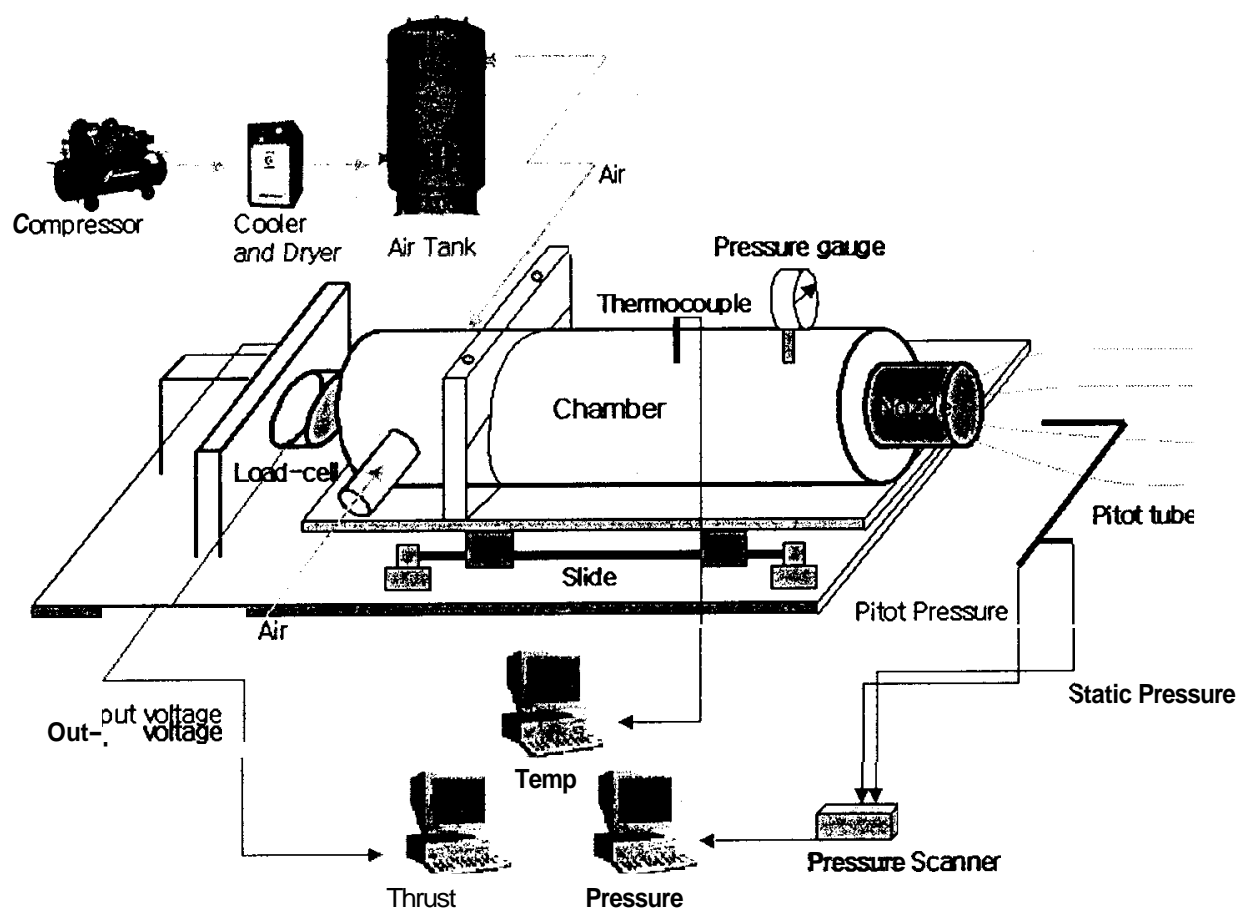

Fig. 13 Experimental schematic of thrust measurement of supersonic wind tunnel

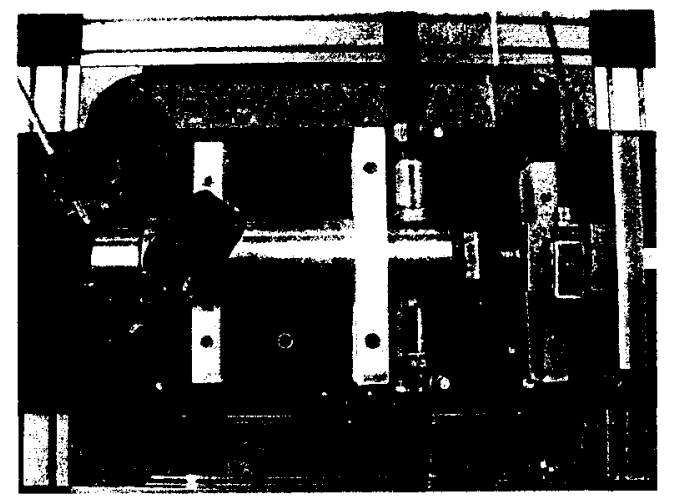

(a) Photograph of installed supersonic wind tunnel on thrust stand

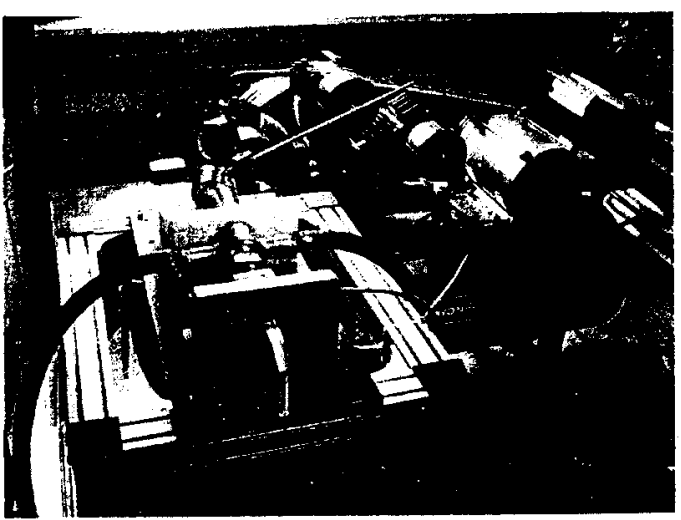

(b) Overview photograph of thrust measurement experiment

Fig. 14 Photograph of thrust measurement system of supersonic wind tunnel 